\title{
Intimate Partner Violence-Related Injuries Among Colombian Women
}

\author{
Nathalia Quiroz Molinares, BS, ${ }^{1,2}$ Julia C. Daugherty, MSc, ${ }^{3}$ Rafael Mejía Villarreal, BS, ${ }^{1}$ \\ Natalia Hidalgo-Ruzzante, $\mathrm{PhD},{ }^{3,4}$ and Carlos José De los Reyes Aragón, PhD ${ }^{1}$
}

\begin{abstract}
Previous studies have reported that the majority of women who suffer physical injuries related to intimate partner violence (IPV) have been injured in the head, neck, and/or face. No studies have provided detailed information on injuries suffered by Colombian abused women, and therefore the types of injuries, where on the body they have been inflicted and the associated symptoms experienced by women who are victims of IPV remain unknown in the Colombian context. This study aims to describe the patterns of injuries among female victims of IPV in Colombia, as well as the related demographic and nondemographic factors. We used reports gathered from the "Centro de Atención a Víctimas de la Fiscalía [Center for Victim Services at the District Attorney's Office]" in the city of Barranquilla, Colombia, between January 2016 and January 2017. We found that most cases involved injuries to the head and face. The implications of this type of injury were discussed.
\end{abstract}

Keywords: intimate partner violence, Colombian women, injuries, review of reports

\section{Introduction}

A CCORding to The World Health ORganization (WHO), intimate partner violence (IPV) refers to "behavior by an intimate partner or ex-partner that causes physical, sexual or psychological harm, including physical aggression, sexual coercion, psychological abuse and controlling behaviors" (WHO 2013). Other authors define it as "behaviors intended to exert power and control over an intimate partner, including physical, sexual, verbal, emotional, and financial abuse" (Ballan and Freyer 2012). While both men and women can potentially be victims of abuse, it is more common for female partners to be subjected to IPV (Ivany and Schminkey 2016). The WHO has shed light on the magnitude and pervasiveness of this issue, reporting that about one in three women worldwide (35\%) have experienced either physical or sexual IPV in their lifetime (WHO 2013).

Previous studies have reported that the majority of women who suffer physical injuries related to IPV have been injured in the head, neck, and/or face (HNF) (Wong et al. 2014). Injuries in these areas are associated with neurological problems, such as axonal damage and cerebral anoxia or hypoxia (Ivany and Schminkey 2016; Kennedy et al. 2007; Valera and Berenbaum 2003; Valera and Kucyi 2017; Wong et al. 2014), which may in turn lead to neuropsychological impairment (Valera and Berenbaum 2003; Valera and Kucyi 2017). Research regarding HNF injuries among women subjected to IPV has found the prefrontal cortex to be one of the cerebral areas most affected by physical abuse (Stein et al. 2002). Damage to this area may explain diminished cognitive functioning found among female victims in the domains of memory, attention, and executive functioning (Jackson et al. 2002; Monahan and O'Leary 1999; Rincón and Fernández 2015; Stein et al. 2002; Twamley et al. 2009). Thus, researching the nature of these injuries is critical to understanding the psychological and neuropsychological consequences of IPV, and even a victim's susceptibility to remaining in the violent relationship (Southwick et al. 2005; Valera and Barenbaum 2003).

Despite the fact that injuries to the HNF have been traditionally considered indicators of IPV (Ochs et al. 1996), there is a lack of studies in the available literature regarding this topic for a variety of reasons. First, many women do not come forward to report instances of aggression due to a myriad of personal and societal reasons, such as

${ }^{1}$ Department of Psychology, Universidad del Norte, Barranquilla, Colombia.

${ }^{2}$ Department of Social Sciences, Universidad de la Costa, Barranquilla, Colombia.

${ }^{3}$ Centro de Investigación Mente, Cerebro y Comportamiento (CIMCYC), Granada, Spain.

${ }^{4}$ Department of Evolutionary Psychology and Education, Universidad de Granada, Granada, Spain. 
embarrassment (Gracia 2004), fear of persecution or of being killed (Delegación del Gobierno para la Violencia de Género 2015), retaliatory threats to hurt or kill the children (Meyer 2012, 2016), unequal societal power relations between men and women, and even a normalization of the situation as a coping strategy (Tiwari et al. 2016; Wong et al. 2014). Second, cases of HNF injuries, such as strangulation, are severely underreported due to their invisible nature (Zilkens et al. 2016). In fact, only half of strangulation victims present physical signs (Strack et al. 2001), and many victims die each year without a visible injury on the exterior of the neck (Hawley et al. 2001; Shields et al. 2010; Smith et al. 2001; Strack et al. 2001).

In Colombia, the National Institute for Legal Medicine and Forensic Science records show 527,284 reported cases of IPV from 2007 to 2017. Although this clearly represents a public health problem, to the best of our knowledge, no study has been made of injury patterns in Colombian women suffering from IPV. Injury patterns can vary across cultures because the intentions of the aggressors when exercising violence can be diverse, including disfiguration, humiliation, and the exercise of power (Restrepo-Bernal et al. 2014; Munevar 2018). Therefore, given the lack of studies of IPV in Latin American countries, this study is a worthwhile step in the general study of the effects of IPV. This study aims to describe the patterns of injuries among female victims of IPV in the Colombian context, as well as the related demographic and nondemographic factors.

\section{Materials and Methods}

In this retrospective study, 170 reports from female victims of IPV were reviewed, as shown in Figure 1. These reports were registered between January 2016 and January 2017 and were gathered from the "Centro de Atención a Víctimas (CAV) de la Fiscalía [Center for Victim Services at the District Attorney's Office]" in the city of Barranquilla, Colombia. This center receives reports from victims

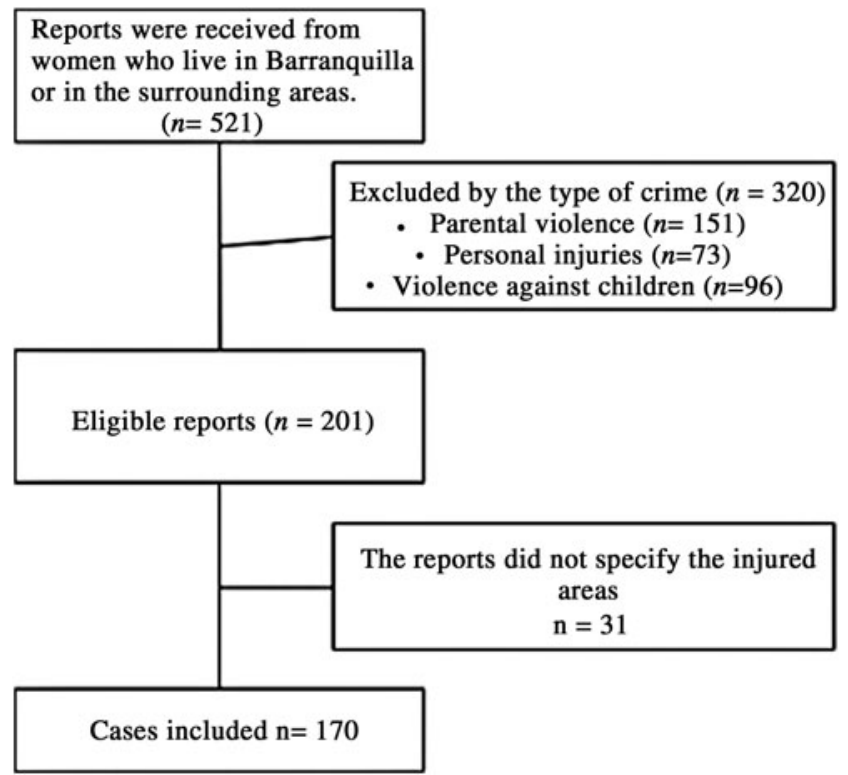

FIG. 1. Eligibility and inclusion flow diagram. of family-related crimes, such as intrafamily violence, parental abuse by children, and IPV. This study includes only those reports of IPV in which aggressions were committed by current partners or ex-partners, regardless of whether they cohabitated with the victim. Incomplete reports or reports from other forms of crime were excluded. The approval for this study was obtained from the Center of Victims Services (Fig. 1).

\section{Data abstraction}

The contents of each report included the type of crime, basic sociodemographic data, and the sites of injury. The reports were analyzed manually. To facilitate data extraction, an abstraction sheet was created to register the following variables extracted from each report: socioeconomic characteristics of the victims, site of the injury, type of injury, and relationship with offender. Demographic information was also gathered from the reports. To ensure the confidentiality of the women's personal information, the analysis was carried out using codes, excluding names and any other identifying personal information.

\section{Data analysis}

A frequency analysis was carried out using the statistics analysis package SPSS 23 to assess sociodemographic information, site of the injury, type of injury, relationship with offender, and so on.

\section{Results}

\section{Participant characteristics}

The average age was 31 years (standard deviation $[\mathrm{SD}]=9.44)$, and the average educational level was 11 years $(\mathrm{SD}=3.2)$ (completion of high school). Most cases of IPV $(88.6 \%)$ were reported in the southern part of the city.

\section{Injuries associated with IPV}

Results shows that in $77.6 \%$ of cases, women acquired injuries to their face and head exclusively. A large percentage $(40 \%)$ received injuries to their limbs, and most of these were caused by a punch with the fist $(80.4 \%)$ or through the use of objects such as weapons, sticks, guns, bottles, and cell phones (30\%), which mainly affect soft tissue. Furthermore, the most common types of injury were bruises (18.3\%) and open wounds (12.4\%). Fractures were also registered, although the percentage was low (1.2\%). Finally, the main symptoms related to traumatic brain injury (TBI) symptomatology, such as headaches (8.9\%), loss of consciousness $(3 \%)$, and nausea and vomiting $(2.4 \%)$, were reported as shown in Table 1.

\section{Cohabitation, repeat abuse, and symptom detection}

Results show that most of the victims were involved in multiple episodes of abuse $(87.8 \%)$ and that most of the victims were no longer cohabitating with the aggressor (54.7\%). There was a marginal difference between cohabitation with the aggressor (yes/no) and repeat abuse (yes/no): $\chi_{(1)}^{2}=2.075, p=0.05$, with a small effect size $(d=0.222)$. Although $77.6 \%$ of the women have lesions in the neck, 
Table 1. Patterns of Injuries Associated with Intimate PARTNER Violence

\begin{tabular}{lc}
\hline Type of violence & $\%$ \\
\hline Punch with the fist & 80.4 \\
Use of object & \\
Weapons & 5.4 \\
Kicking & 9.4 \\
Strangling & 11.4 \\
Area of the injury & \\
Face & 50 \\
Head & 35.8 \\
Neck & 13 \\
Chest & 10 \\
Abdominal & 3 \\
Back & 13 \\
Limbs & 40 \\
Dorsum & 3 \\
Hip & 2 \\
Anal/genital & 1.8 \\
Multiple areas & 5 \\
Verbal aggression exclusively & 3.6 \\
Reported symptoms related to TBI & \\
Headache & 8.9 \\
Nausea/vomiting & 2.4 \\
Loss of consciousness & 3 \\
Type of injuries & \\
Burns & 0.6 \\
Laceration & 1.2 \\
Open wound & 0.5 \\
Bruises & 3 \\
Fracture & \\
Fecal incontinence & \\
Head protuberance & \\
\hline & \\
&
\end{tabular}

TBI, traumatic brain injury.

head, and face areas, only $35 \%$ report at least one symptom related to TBI.

\section{Discussion}

The aims of this study were to describe the patterns of physical injuries among female victims of IPV in the Colombian context and to examine these injuries through a descriptive analysis of demographic and nondemographic characteristics of the victims (e.g., site of the injury, type of injury, and relationship with offender). We found that injuries to the head and face were the most common types and that in most cases the injuries were caused by a punch with the fist. Also, only $35 \%$ of the women reported symptoms related to TBI, and these kinds of symptoms were reported mostly $(85 \%)$ in cases of women who have suffered more than two episodes of violence.

These results are similar to those found in the United States (Monahan and O'Leary 1999; Mulleman et al. 1996) and Hong Kong (Wong et al. 2014), in which a high percentage of women have been found to suffer IPV in the form of physical aggression with common injuries to the HNF. Injuries to the HNF are considered indicators of TBI, which can provoke neurological deficiencies (Goldin et al. 2016). It is also worth mentioning that the second most common site of injury was the limbs. This finding is similar to the results of another study conducted in Latin America (Tocci and Saavedra 2009), which found that it is common for women to be hurt in this particular area when trying to defend themselves from their aggressor.

Despite the fact that only $35 \%$ of the women reported at least one symptom related to TBI, $85 \%$ of these were women who reported multiple episodes of violence. These findings are similar to those of Wong et al. (2014), who found that more than half of abused women $(70 \%)$ reported multiple episodes of abuse when they entered emergency services. This result may indicate that many of the injuries received are neither highly visible nor of great consequence in a single event. This situation has been studied in football players and boxers, showing that repeated blows to the head may produce rotational acceleration of the brain (shearing forces in the brain tissues), diffuse axonal damage, and other types of brain damage (Mendez 1995). These accumulative effects have been associated with chronic traumatic encephalopathy (Campbell et al. 2017).

In addition to these findings, women who cohabitate with the aggressor seem to be at risk of suffering multiple episodes of violence. Although the level of significance did not reach the marginal level, these findings are similar to those of Wong et al. (2014), who found that women who cohabitate with their aggressor were at much greater risk of being revictimized.

It is necessary to mention some limitations of this study. First, the study was conducted only in Barranquilla. Therefore, there may be sampling biases, which do not permit generalizability to the Colombian population at large, despite the fact that Barranquilla has the fourth highest number of cases of IPV of all cities in Colombia (Instituto Nacional de Medicina legal y Ciencias Forenses [National Institute for Legal Medicine and Forensic Science] 2017). Second, our sample is limited to reported cases and thus excludes cases that have not been registered by the CAV. Considering the fact that many women do not report IPV due to threats and fears of persecution (Gracia 2004), future research should consider reaching this population through other means to compare the physical injuries found in this study with those found in unreported cases.

Despite these limitations, our results show the relevance of studying injury patterns in the Colombian population, as it is known that these types of injuries are related to TBIs and possible neurological and neuropsychological impairment. We are beginning to understand the importance of injury patterns in women who have been subjected to IPV. For health care professionals, this can be useful to improve the assessment of women with physical injuries, to provide better attention protocols, and to promote awareness of IPV dangers. The results could also be useful for hospitals, victims' services centers, and police stations to show where they should give special attention when they are presented with a new case of IPV. This may improve the safety of women who have suffered violence and help to prevent further injuries. The study may also provide input to public policies related to improved access to health services and the provision of the necessary assessment and diagnostic tools for women who have suffered from IPV. Further studies should consider exploring the emotional, behavioral, and cognitive functions affected by HNF injuries in female victims, and how the brain is affected by IPV. It is important 
that this includes an assessment of the long-term effects of these types of injuries.

In conclusion, the head and face were the most common sites of IPV injuries, which is consistent with the findings of previous studies. Symptoms related to TBI are generally not reported; however, women who were injured in the HFN area tended to suffer multiple episodes of abuse. Such repetition may be related to brain damage by multiple contusions, such as that seen in boxers and footballers.

\section{Author Disclosure Statement}

No competing financial interests exist.

\section{References}

Ballan MS, Freyer MB. (2012). Self-defense among women with disabilities. Violence Against Women. 18, 1083-1107.

Campbell JC, Anderson JC, McFadgion A, et al. (2017). The effects of intimate partner violence and probable traumatic brain injury on central nervous system symptoms. J Womens Health. 27, 761-767.

Evaluation of neuropsychological deterioration in a sample of women victims of gender violence [in Spanish]. National Institute for Legal Medicine and Forensic Science. (2017). Forensis (19). Retrived from http://www.medicinalegal.gov.co/documents/20143/ 262076/Forensis+2017+Interactivo.pdf/0a09fedb-f5e8-11f8-71ed$2 \mathrm{~d} 3 \mathrm{~b} 475 \mathrm{e} 9 \mathrm{~b} 82$

Goldin Y, Haag HL, Trott CT. (2016). Screening for history of traumatic brain injury among women exposed to intimate partner violence. PM R. 8, 1104-1110.

Government Delegation for Gender Violence. (2015). On the inhibition to denounce the victims of gender violence [in Spanish]. Madrid: Ministry of Health, Social Services and Equality.

Gracia E. (2004). Unreported cases of domestic violence against women: Towards an epidemiology of social silence, tolerance, and inhibition. J Epidemiol Commun Health. 58, 536-537.

Hawley DA, McClane GE, Strack GB. (2001). A review of 300 attempted strangulation cases: Part III. Injuries in fatal cases. J Emerg Med. 21, 317-322.

Ivany A, Schminkey D. (2016). Intimate partner violence and traumatic brain injury. Fam Community Health. 39, 129-137.

Jackson H, Philp E, Nuttall RL, Diller L. (2002). Traumatic brain injury: A hidden consequence for battered women. Prof Psychol. 33, 39-45.

Kennedy JE, Jaffee MS, Leskin GA, et al. (2007). Posttraumatic stress disorder and posttraumatic stress disorder-like symptoms and mild traumatic brain injury. J Rehabil Res Dev. 44, 895-920.

Mendez MF. (1995). The neuropsychiatric aspects of boxing. Int J Psychiatry Med. 25, 249-262.

Meyer S. (2012). Why women stay: A theoretical examination of rational choice and moral reasoning in the context of intimate partner violence. Aust N Z J Criminol. 45, 179-193.

Meyer S. (2016). Still blaming the victim of intimate partner violence? Women's narratives of victim desistance and redemption when seeking support. Theor Criminol. 20, 75-90.

Monahan K, O'Leary D. (1999). Head injury and battered women: An initial inquiry. Health Soc Work. 24, 269-278.

Mulleman R, Lenaghan P, Pakisier R. (1996). Battered women: Injury locations and types. Ann Emerg Med. 28, 486-492.

Munevar DI. (2018). Crimes of femicide and femicide in Latin American countries [in Spanish]. Revista Brasileira de Sociologia do Direito. 5, 46-72.
Ochs HA, Neuenschwander MC, Dodson TB. (1996). Are head, neck and facial injuries markers of domestic violence? J Am Dent Assoc. 127, 757-761.

Restrepo-Bernal D, Gómez-González A, Gaviria SL. (2014). Intentional burns with acid. New expressions of violence against women in Medellín, Colombia [in Spanish]. Cases Series. V Xerte. 25, 179-185. Rincón BR, Fernández MP. (2015). Evaluation of neuropsychological deterioration in a sample of women victims of gender violence [in Spanish]. (Doctoral Thesis). Universidad de Salamanca, Salamanca, Spain.

Shields LB, Corey TS, Weakley-Jones B, Stewart D. (2010). Living victims of strangulation: a 10-year review of cases in a metropolitan community. Am J Forensic Med Pathol. 31, 320-325.

Smith DJ, Mills T, Taliaferro EH. (2001). Frequency and relationship of reported symptomatology in victims of intimate partner violence: The effect of multiple strangulation attacks. J Emerg Med. 21, 223 329.

Southwick SM, Vythilingam M, Charney DS. (2005). The psychobiology of depression and resilience to stress: implications for prevention and treatment. Annu Rev Clin Psychol. 1, 255-291.

Stein MB, Kennedy CM, Twamley EW. (2002). Neuropsychological function in female victims of intimate partner violence with and without posttraumatic stress disorder. Biol Psychiatry. 52, 10-11.

Strack GB, McClane GE, Hawley D. (2001). A review of 300 attempted strangulation cases Part I: Criminal legal issues. J Emerg Med. 21, 303-309.

Tiwari A, Wong M, Ip H. (2016). Ren and Yuan: A cultural interpretation of Chinese women's responses to battering. Can J Nurs Res. 33, 63-79.

Tocci N, Saavedra G. (2009). Epidemiological characteristics of the cases of mistreatment of women treated in the forensic medicine service of the hospital "Dr. Adolfo Prince Lara" period 2006-2008 municipality of Puerto Cabello-Edo Carabobo [in Spanish]. Faculty of Juridical and Political Sciences. 59, 615-633.

Twamley EW, Allard CB, Thorp SR, et al. (2009). Cognitive impairment and functioning in PTSD related to intimate partner violence. J Int Neuropsychol Soc. 15, 879-887.

Valera EM, Berenbaum H. (2003). Brain injury in battered women. J Consult Clin Psychol. 71, 797-804.

Valera E, Kucyi A. (2017). Brain injury in women experiencing intimate partner-violence: neural mechanistic evidence of an "invisible" trauma. Brain Imaging and Behav. 11, 1664-1677.

Wong JY-H, Choi AW-M, Fong DY-T, et al. (2014). Patterns, aetiology and risk factors of intimate partner violence-related injuries to head, neck and face in Chinese women. BMC Womens Health. 14, 6.

World Health Organization (WHO). (2013). Violence against women. Retrieved from www.who.int/mediacentre/factsheets/fs239/es

Zilkens RR, Phillips MA, Kelly MC, et al. (2016). Non-fatal strangulation in sexual assault: A study of clinical and assault characteristics highlighting the role of intimate partner violence. J Forensic Leg Med. 43, 1-7.

Address correspondence to: Nathalia Quiroz Molinares, BS Department of Psychology Universidad del Norte Barranquilla 080002

Colombia

E-mail: nathaliaq@uninorte.edu.co 